\title{
PENGARUH PELATIHAN DAN PENERAPAN MODEL METODE ASUHAN KEPERAWATAN PROFESIONAL (MAKP) PRIMARY NURSING TERHADAP KUALITAS ASUHAN KEPERAWATAN DI RUMAH SAKIT KOTA MEDAN
}

\author{
Hendry Kiswanto Mendrofa, Lammurni Sagala \\ Program Studi Ilmu Keperawatan, STIKes Murni Teguh \\ E-mail : hendrykiswanto155@gmail.com \\ Program Studi Ilmu Keperawatan, STIKes Murni Teguh \\ E-mail : lammurnisagala@yahoo.com
}

\begin{abstract}
Improving quality nursing care has become a major concern for all professional health care providers and consumers, research and literature on the quality of providing nursing care is still underdeveloped, especially in Indonesia. The model of primary nursing care (MAKP) nursing method is an assignment method where nurses are responsible to patients for 24 hours from the time the patient enters into discharge, this method embodies the independence of the nurses in implementing care and the model of primary nursing care (MAKP) method of nursing can increase the quality of nursing care services, the purpose of this study was to analyze the effect of the model of primary nursing care (MAKP) primary nursing methods on the quality of nursing care. This research is a Quasi Experimental Study with non-equivalent control group pretest-posttest design that is observing the effect of using the intervention and control groups without subject randomization. The population in this study were nurses who worked in inpatient and inpatient installations, the sampling technique in this study used purposive sampling technique. Data collection on the quality of nursing care using the Patient's Assessment of Quality Scale - Acute Care Version (PAQS-ACV) instrument, based on the results of the Content Validity Index (CVI) test of the Patient's Assessment of Quality Scale - Acute Care Version (PAQS-ACV) instrument was 0.98 and the results The reliability test of the Patient's Assessment of Quality Scale - Acute Care Version (PAQS-ACV) questionnaire obtained a Cronbach Alpha value of 0.66. The results showed that there was an influence on the application of the primary nursing care professional model (MAKP) primary nursing on improving the quality of nursing care, based on the results of the independent $t$-test, it was found that the sig (2-tailed) value was 0.00 where $<0.05$, it could be concluded that there were differences Significant between the quality of nursing care in the intervention group with the quality of nursing care in the control group, it is recommended that all hospitals, especially in North Sumatra, apply the model of primary nursing care method (MAKP) in primary nursing in the implementation of nursing duties in the inpatient room.
\end{abstract}

Keywords : Professional Nursing Care Model, Primary Nursing, Quality of Nursing Care

\begin{abstract}
Abstrak
Meningkatkan asuhan keperawatan yang berkualitas telah menjadi perhatian utama bagi semua penyedia layanan kesehatan profesional dan konsumen, penelitian dan literatur tentang kualitas pemberian asuhan keperawatan masih belum berkembang khususnya di Indonesia. Model metode asuhan keperawatan (MAKP) primary nursing merupakan metode penugasan dimana perawat bertanggung jawab kepada pasien selama 24 jam mulai saat pasien masuk sampai dengan keluar, metode ini mewujudkan kemandirian para perawat dalam melaksakan asuhan dan model metode asuhan keperawatan (MAKP) primary nursing dapat meningkatkan kualitas pelayanan asuhan keperawatan, Tujuan dari penelitian ini adalah menganalisis pengaruh model metode asuhan keperawatan profesional (MAKP) primary nursing terhadap kualitas asuhan keperawatan. Penelitian ini merupakan jenis penelitian Quasi Exsperimental Study dengan desain pretest-posttest non equivalent control group yaitu mengobservasi pengaruh dengan menggunakan kelompok
\end{abstract}


intervensi dan kontrol tanpa randomisasi subjek. Populasi dalam penelitian ini yaitu perawat yang bekerja di instalasi rawat inap dan pasien rawat inap, teknik pengambilan sampel dalam penelitian ini menggunakan teknik purposive sampling. Pengumpulan data kualitas asuhan keperawatan menggunakan instrumen Patient's Assessment of Quality Scale - Acute Care Version (PAQSACV), berdasarkan hasil uji Content Validity Index (CVI) instrumen Patient's Assessment of Quality Scale - Acute Care Version (PAQS-ACV) adalah 0.98 dan hasil uji reliabilitas kuesioner Patient's Assessment of Quality Scale - Acute Care Version (PAQS-ACV) didapatkan nilai Cronbach Alpha yaitu 0,66. Hasil penelitian menunjukkan bahwa ada pengaruh penerapan model metode asuhan keperawatan profesional (MAKP) primary nursing terhadap peningkatan kualitas asuhan keperawatan, berdasarkan hasil uji independend $t$-test di ketahui nilai sig (2-tailed) sebesar 0.00 dimana $<0.05$ maka dapat disimpulkan bahwa ada perbedaan yang signifikan antara kualitas asuhan keperawatan pada kelompok intervensi dengan kualitas asuhan keperawatan pada kelompok kontrol, disarankan untuk seluruh rumah sakit khususnya wilayah sumatera utara menerapkan model metode asuhan keperawatan profesional (MAKP) primary nursing dalam pelaksanaan tugas keperawatan di ruang rawat inap.

Kata Kunci : Model Asuhan Keperawatan Profesional, Primary Nursing, Kualitas Asuhan Keperawatan

\section{PENDAHULUAN}

Meningkatkan asuhan keperawatan yang berkualitas telah menjadi perhatian utama bagi semua penyedia layanan kesehatan profesional dan konsumen (Zhao, Akkadechanunt dan Xue, 2008), oleh sebab itu pemberian pelayanan keperawatan yang berkualitas menjadi penting dalam layanan kesehatan saat ini, penelitian dan literature tentang kualitas pemberian asuhan keperawatan masih belum berkembang khususnya di Indonesia dan ada kekurangan informasi tentang bagaimana kualitas asuhan keperawatan yang sesungguhnya diberikan, kepuasan pasien menjadi salah satu indikator yang sering digunakan untuk menilai kualitas pelayanan yang diberikan (Lynn, McMillen dan Sidani, 2008), mengungkapkan hasil kepuasan pasien sebagai alat untuk menilai kualitas keperawatan tidak memadai dan dangkal untuk mengukur kualitas pelayanan karena kepuasan pasien adalah fenomena yang kompleks meskipun kepuasan pasien merupakan masukan penting dari pasien mengenai perawatan yang mereka terima (Izumi, Baggs, dan Knafl, 2011).

Model metode asuhan keperawatan (MAKP) primary nursing merupakan metode penugasan dimana perawat bertanggung jawab kepada pasien selama 24 jam mulai saat pasien masuk sampai dengan keluar, metode ini mewujudkan kemandirian para perawat dalam melaksakan asuhan (Nursalam, 2014), dan model metode asuhan keperawatan (MAKP) primary nursing dapat meningkatkan kualitas pelayanan asuhan keperawatanya itu secara signifikan dapat menurunkan angka kejadian Infeksi kateter urine, flebitis, angka kejadian jatuh dan kejadian decubitus (Molin et al, 2018)

Berdasarkan hasil wawancara peneliti terhadap kepala unit keperawatan di beberapa rumah sakit di Kota Medan tentang model dalam penugasan perawat, dari hasil tersebut peneliti mendapatkan mayoritas unit keperawatan belum melaksanakan model metode asuhan keperawatan (MAKP) primary nursing, unit keperawatan masih menggunakan metode Tim dalam pelaksanaan penugasan para perawat, mereka menyatakan bahwa mereka belum melaksanakan metode primer karena belum mendapatkan pelatihan tentang bagaimana model penugasan primary nursing dan tidak mengetahui pengaruh dari model yang digunakan dan bagaimana model itu diterapkan dalam layanan keperawatan

\section{METODE PENELITIAN}

Jenis penelitian ini adalah Quasi Exsperimental Study dengan desain pretestposttest non equivalent control group yaitu 
mengobservasi pengaruh dengan menggunakan kelompok intervensi dan kontrol tanpa randomisasi subjek (Polit dan Beck, 2012). Populasi dalam penelitian ini yaitu perawat yang bekerja di instalasi rawat inap dan pasien di ruang rawat inap. teknik pengambilan sampel dengan menggunakan teknik purposive sampling yaitu peneliti sengaja memutuskan untuk memilih orangorang yang dinilai menjadi khas dari populasi atau sangat berpengetahuan tentang masalah yang akan diteliti (Polit dan Beck, 2012), metode analisis data untuk menganalisis antara dua variabel untuk mengetahui apakah ada pengaruh intervensi/pelatihan terhadap kualitas asuhan keperawatan, sebelum (pretest) dan sesudah (pos-test) pemberian intervensi, maka uji yang digunakan dalam penelitian ini adalah uji statistik parametrik yaitu independent t-test dan paired t-test, Sebelum melakukan uji, peneliti melakukan uji normalitas dengan menggunakan uji Kolmorogov-Smirnov test dengan nilai kemaknaan $(\mathrm{p}>0,05)$.

\section{HASIL PENELITIAN}

Berikut akan diuraikan data hasil penelitian pengaruh pelatihan dan penerapan model metode asuhan keperawatan profesional (MAKP) primary nursing terhadap kualitas asuhan keperawatan di rumah sakit kota Medan. Pengumpulan data dilaksanakan pada 68 responden, penyajian data meliputi karakteristik data demografi responden dan data distribusi frekuensi kualiatas asuhan keperawatan pada kelompok intervensi dan kontrol dan hasil uji independent t-test dan paired t-test pada kelompok intervensi dan kontrol.

\section{Karakteristik Pasien Kelompok Intervensi di Ruang Rawat Inap $(n=68)$}

Berdasarkan hasil penelitian terhadap 68 responden, akan disajikan distribusi karakteristik sebagai berikut :

Tabel 1. Karakteristik Pasien di Ruang Rawat Inap pada kelompok intervensi $(n=68)$

\begin{tabular}{clcc}
\hline No & Karakteristik & $\begin{array}{c}\text { Frekuensi } \\
(f)\end{array}$ & $\begin{array}{c}\text { Persentase } \\
(\%)\end{array}$ \\
\hline 1 & Usia & & \\
& < 20 Tahun & 4 & 5.9 \\
& 20-40 Tahun & 30 & 44.1 \\
& 41-60 Tahun & 27 & 39.7 \\
& >60 Tahun & 7 & 10.3 \\
2 & Jenis Kelamin & & \\
& Perempuan & 32 & 47.1 \\
& Laki-Laki & 36 & 52.9 \\
3 & Tingkat & & \\
& Pendidkan & & \\
& SD & 3 & 4.4 \\
& SMP & 11 & 16.2 \\
& SMA & 46 & 67.6 \\
& Perguruan & 8 & 11.8 \\
& Tinggi & & \\
Lama Dirawat & & \\
& 1-3 Hari & 24 & 50 \\
& 4-7 Hari & 31 & 65.6 \\
& > 7 Hari & 3 & 4.4 \\
\hline
\end{tabular}

Tabel diatas menunjukkan bahwa berdasarkan usia mayoritas responden berumur 20-40 Tahun sebanyak 30 orang (44.1 \%), berdasarkan jenis kelamin mayoritas responden adalah laki-laki sebanyak 36 orang $(52.9 \%)$, berdasarkan tingkat pendidikan mayoritas responden memiliki tingkat pendidikan terakhir adalah SMA sebanyak 46 orang $(67.6 \%)$ dan mayoritas responden telah dirawat 4-7 hari sebanyak 31 orang $(65.6 \%)$

\section{Karakteristik Pasien Kelompok Kontrol di Ruang Rawat Inap $(n=68)$}

Berdasarkan hasil penelitian terhadap 68 responden, akan disajikan distribusi karakteristik sebagai berikut :

Tabel 2 Karakteristik Pasien di Ruang Rawat Inap pada kelompok kontrol $(\mathrm{n}=68)$

\begin{tabular}{llcc}
\hline No & Karakteristik & $\begin{array}{c}\text { Frekuensi } \\
(\boldsymbol{f})\end{array}$ & $\begin{array}{c}\text { Persentase } \\
(\boldsymbol{\%})\end{array}$ \\
\hline 1 & Usia & & \\
& < 20 Tahun & 3 & 4.4 \\
& 20-40 Tahun & 31 & 45.6 \\
& 41-60 Tahun & 25 & 36.8 \\
& >60 Tahun & 9 & 13.2 \\
2 & Jenis Kelamin & & \\
& Perempuan & 35 & 51.5 \\
& Laki-Laki & 32 & 47.1 \\
\hline
\end{tabular}




\begin{tabular}{llcc}
\hline $3 \quad$ Tingkat & & \\
& Pendidkan & & \\
& SD & 1 & 1.5 \\
SMP & 13 & 19.1 \\
& SMA & 37 & 54.4 \\
& Perguruan Tinggi & 17 & 25.0 \\
4 & Lama Dirawat & & \\
& 1-3 Hari & 24 & 35.3 \\
& 4-7 Hari & 36 & 52.9 \\
& $>7$ Hari & 8 & 11.8 \\
\hline
\end{tabular}

Tabel diatas juga menunjukkan bahwa berdasarkan usia mayoritas responden berumur 20-40 Tahun sebanyak 31 orang (45.6\%), berdasarkan jenis kelamin, mayoritas perempuan sebanyak 17 orang (51.5\%), berdasarkan tingkat pendidikan mayoritas responden memiliki tingkat pendidikan terakhir adalah SMA sebanyak 37 orang $(54.4 \%)$ dan mayoritas responden telah dirawat 4-7 hari sebanyak 36 orang $(52.9 \%)$.

\section{Analisa Unvariat}

Distribusi Frekuensi Kualitas Asuhan Keperawatan di Ruang Rawat inap Sebelum Intervensi Pada Kelompok Intervensi $(\mathbf{n}=\mathbf{3 4})$

Berdasarkan hasil penelitian terhadap 34 responden akan disajikan distribusi kualitas asuhan keperawatan sebelum intervensi pada kelompok intervensi, untuk masing-masing kategori dapat dilihat pada tabel berikut :

Tabel. 3. Distribusi Frekuensi Kualitas Asuhan Keperawatan di Ruang Rawat inap Sebelum Intervensi Pada Kelompok Intervensi $(\mathrm{n}=34)$

\begin{tabular}{cccc}
\hline No. & $\begin{array}{c}\text { Kualitas } \\
\text { Asuhan }\end{array}$ & $\begin{array}{c}\text { Frekuensi } \\
(\boldsymbol{f})\end{array}$ & Persentase (\%) \\
\hline 1. & Tinggi & 23 & 67.6 \\
2. & Sedang & 11 & 32.3 \\
3. & Rendah & - & - \\
\hline & Jumlah & 34 & 100,0 \\
\hline
\end{tabular}

Hasil penelitian pasien telah disajikan pada tabel diatas menunjukkan bahwa kualitas asuhan keperawatan di Ruang Rawat Inap Kelas sebelum intervensi pada kelompok intervensi yaitu mayoritas berada pada kategori tinggi yaitu sebesar $68.5 \%$.
Distribusi Frekuensi Kualitas Asuhan Keperawatan Di Ruang Rawat Inap Sesudah Intervensi Pada Kelompok Intervensi $(n=34)$

Berikut akan disajikan distribusi kualitas asuhan keperawatan sesudah intervensi pada kelompok intervensi, untuk masing-masing kategori dapat dilihat pada tabel berikut :

Tabel. 4.Distribusi Frekuensi Kualitas Asuhan Keperawatan di Ruang Rawat Inap Sesudah Intervensi Pada Kelompok Intervensi $(\mathrm{n}=34)$

\begin{tabular}{clcc}
\hline No. & $\begin{array}{c}\text { Kualitas } \\
\text { Asuhan }\end{array}$ & $\begin{array}{c}\text { Frekuensi } \\
(\boldsymbol{f})\end{array}$ & $\begin{array}{c}\text { Persentase } \\
(\boldsymbol{\%})\end{array}$ \\
\hline 1. & Tinggi & 34 & 100 \\
2. & Sedang & - & - \\
3. & Rendah & - & - \\
\hline & Jumlah & 34 & 100,0 \\
\hline
\end{tabular}

Hasil penelitian pasien telah disajikan pada tabel diatas menunjukkan bahwa kualitas asuhan keperawatan di Ruang Rawat Inap Kelas setelah intervensi pada kelompok intervensi seluruhnya berkategori tinggi (100\%).

\section{Distribusi Frekuensi Kualitas Asuhan} Keperawatan di Ruang Rawat inap Sebelum Intervensi Pada Kelompok Kontrol $(\mathbf{n}=34)$

Hasil penelitian terhadap 34 responden akan disajikan distribusi kualitas asuhan keperawatan sebelum intervensi pada kelompok kontrol, untuk masing-masing kategori dapat dilihat pada tabel berikut :

Tabel 5.Distribusi Frekuensi Kualitas Asuhan Keperawatan di Ruang Rawat inap Sebelum Intervensi Pada Kelompok kontrol $(\mathrm{n}=34)$

\begin{tabular}{clcc}
\hline No. & $\begin{array}{c}\text { Kualitas } \\
\text { Asuhan }\end{array}$ & $\begin{array}{c}\text { Frekuensi } \\
(\boldsymbol{f})\end{array}$ & $\begin{array}{c}\text { Persentase } \\
(\boldsymbol{\%})\end{array}$ \\
\hline 1. & Tinggi & 19 & 55.8 \\
2. & Sedang & 14 & 41.7 \\
3. & Rendah & 1 & 2.5 \\
\hline & Jumlah & 34 & 100,0 \\
\hline
\end{tabular}

Hasil penelitian pasien telah disajikan pada tabel diatas menunjukkan bahwa kualitas asuhan keperawatan di Ruang Rawat Inap Kelas sebelum intervensi pada 
kelompok Kontrol yaitu mayoritas berada pada kategori tinggi yaitu sebesar 55.8.

\section{Distribusi Frekuensi Kualitas Asuhan Keperawatan di Ruang Rawat inap sesudah Intervensi Pada Kelompok Kontrol $(\mathbf{n}=34)$}

Kualitas asuhan keperawatan setelah intervensi pada kelompok kontrol, untuk masing-masing kategori dapat dilihat pada tabel berikut :

Tabel. 6. Distribusi Frekuensi Kualitas Asuhan Keperawatan di Ruang Rawat inap Sebelum Intervensi Pada Kelompok kontrol $(\mathrm{n}=34)$

\begin{tabular}{clcc}
\hline No. & $\begin{array}{c}\text { Kualitas } \\
\text { Asuhan }\end{array}$ & $\begin{array}{c}\text { Frekuensi } \\
(\boldsymbol{f})\end{array}$ & $\begin{array}{c}\text { Persentase } \\
(\boldsymbol{\%})\end{array}$ \\
\hline 1. & Tinggi & 21 & 61.8 \\
2. & Sedang & 13 & 38.2 \\
3. & Rendah & - & - \\
\hline \multicolumn{2}{c}{ Jumlah } & 34 & 100,0 \\
\hline
\end{tabular}

Hasil penelitian pasien telah disajikan pada tabel diatas menunjukkan bahwa kualitas asuhan keperawatan di Ruang Rawat Inap Kelas sesudah intervensi pada kelompok Kontrol yaitu mayoritas berada pada kategori tinggi yaitu sebesar 61.8.

\section{Uji Distribusi Normal}

Uji distribusi normal sebagai syarat untuk dapat melaksanakan uji parametrik yaitu uji Independend dan paired T-Test, Setelah dilakukan uji normalitas dengan uji Kolmorov Smirnov, berdasarkan hasil penelitian menunjukkan bahwa nilai signifikansi ( $p)$ untuk kualitas asuhan keperawatan sebelum dan sesudah intevensi pada kelompok intervensi sebesar 0.200 dan kualitas asuhan keperawatan sebelum dan sesudah intevensi pada kelompok kontrol 0.200 , nilai $p$ untuk kedua variabel $>0,05$, maka disimpulkan data berdistribusi normal.

\section{Analisis Bivariat}

\section{Uji Beda Mean Dengan Menggunakan Uji Independend T-Tes Kelompok Pre Intevensi dengan Kelompok Pre Kontrol}

Hasil penelitian ini untuk mengetahui pengaruh pelatihan dan penerapan model metode asuhan keperawatan profesional
(MAKP) primary nursing terhadap kualitas asuhan keperawatan sebelum melakukan intervensi pada kelompok pre intervensi dan kelompok pre kontrol.

Tabel 7. Uji Beda Mean Dengan Menggunakan Uji Independend T-Test Nilai Kualitas Asuhan Keperawatan Sebelum Intevensi Pada Kelompok Intervensi Dengan Nilai Kualitas Asuhan Keperawatan Sebelum Intervensi Pada Kelompok Kontrol

\begin{tabular}{lcccc}
\hline $\begin{array}{l}\text { Kualitas } \\
\text { Asuhan }\end{array}$ & Mean & $\begin{array}{c}\text { Mean } \\
\text { Differen } \\
\text { Keperawat } \\
\text { an }\end{array}$ & $\begin{array}{c}\text { Levene's } \\
\text { Test for } \\
\text { Equality } \\
\text { of } \\
\text { Variance } \\
\boldsymbol{s}\end{array}$ & Sig. \\
\hline $\begin{array}{l}\text { Sebelum } \\
\text { Intevensi }\end{array}$ & 138. & 3.91 & & \\
$\begin{array}{l}\text { Pada } \\
\text { Kelompok }\end{array}$ & 6 & & & \\
Intervensi & & & & .28 \\
\cline { 1 - 2 } $\begin{array}{l}\text { Sebelum } \\
\text { Intevensi }\end{array}$ & 134. & 3.91 & .796 & 2 \\
Pada & 7 & & & \\
Kelompok & & & & \\
Kontrol & & & & \\
\hline
\end{tabular}

Berdasarkan tabel diatas hasil menunjukkan bahwa nilai rata - rata (mean) kualitas asuhan keperawatan sebelum intevensi pada kelompok intervensi adalah 138.6 dan kualiatas asuhan keperawatan sebelum intervensi pada kelompok kontrol adalah 134.7 dari hasil tersebut dapat menunjukkan bahwa secara statistik deskriptif dapat disimpulkan bahwa tidak ada perbedaan yang berarti antara kualitas asuhan keperawatan sebelum intevensi pada kelompok intervensi dengan kualitas asuhan keperawatan sebelum intevensi pada kelompok kontrol, hasil dari levene's test for equality of variances adalah 0.796 dimana > 0.05 maka varian dari kedua kelompok tersebut diatas adalah homogen dan diketahuai nilai mean di Difference yaitu 3.91 artinya selisih antara nilai rata rata pada kelompok diatas adalah 3.91.

Berdasarkan hasil uji independend $t$ test di ketahui nilaI sig (2-tailed) sebesar 0.282 dimana $>0.05$ maka dapat disimpulkan bahwa tidak ada perbedaan yang signifikan antara kualitas asuhan keperawatan sebelum 
intevensi pada kelompok intervensi dengan kualitas asuhan keperawatan sebelum intevensi pada kelompok kontrol.

Uji Beda Mean dengan Menggunakan Uji Independend T-Test sesudah dilakukan Intervensi pada Kelompok Post Intevensi dengan Kelompok Post Kontrol

Hasil penelitian ini untuk mengetahui pengaruh pelatihan dan penerapan model metode asuhan keperawatan profesional (MAKP) primary nursing terhadap kualitas asuhan keperawatan sesudah melakukan intervensi pada kelompok post intervensi dan kelompok post kontrol.

Tabel 8. Uji Beda Mean Dengan Menggunakan Uji Independend T-Test Nilai Kualitas Asuhan Keperawatan sesudah dilakukan Intervensi pada Kelompok Post Intevensi dengan Kelompok Post Kontrol

\begin{tabular}{|c|c|c|c|c|}
\hline $\begin{array}{l}\text { Kualitas } \\
\text { Asuhan } \\
\text { Keperawat } \\
\text { an }\end{array}$ & Mean & $\begin{array}{c}\text { Mean } \\
\text { Differen } \\
\text { ce }\end{array}$ & $\begin{array}{c}\text { Levene' } \\
\text { s Test } \\
\text { for } \\
\text { Equalit } \\
y \text { of } \\
\text { Varianc } \\
\text { es }\end{array}$ & Sig \\
\hline $\begin{array}{l}\text { Sesudah } \\
\text { Intevensi } \\
\text { Pada } \\
\text { Kelompok } \\
\text { Intervensi }\end{array}$ & $\begin{array}{c}164 . \\
2\end{array}$ & 28.3 & \multirow[t]{2}{*}{.64} & \multirow{2}{*}{$\begin{array}{l}.00 \\
0\end{array}$} \\
\hline $\begin{array}{l}\text { Sesudah } \\
\text { Intevensi } \\
\text { Pada } \\
\text { Kelompok } \\
\text { Kontrol }\end{array}$ & $\begin{array}{c}135 \\
8\end{array}$ & 28.3 & & \\
\hline
\end{tabular}

Hasil menunjukkan bahwa nilai rata rata (mean) kualitas asuhan keperawatan sebelum intevensi pada kelompok intervensi adalah 164.2 dan kualiatas asuhan keperawatan sebelum intervensi pada kelompok kontrol adalah 135.8 dari hasil tersebut dapat menunjukkan bahwa secara statistik deskriptif dapat disimpulkan bahwa ada perbedaan yang berarti antara kualitas asuhan keperawatan sesudah intevensi pada kelompok intervensi dengan kualitas asuhan keperawatan sesudah intevensi pada kelompok kontrol, hasil dari levene's test for equality of variances adalah 0.64 dimana >
0.05 maka varian dari kedua kelompok tersebut diatas adalah homogen dan diketahuai nilai mean di difference yaitu 28.3 artinya selisih antara nilai rata rata pada kelompok diatas adalah 28.3

Berdasarkan hasil uji independend t-test di ketahui nilai sig (2-tailed) sebesar 0.00 dimana $<0.05$ maka dapat disimpulkan bahwa ada perbedaan yang signifikan antara kualitas asuhan keperawatan sesudah intevensi pada kelompok intervensi dengan kualitas asuhan keperawatan sesudah intevensi pada kelompok kontrol.

Uji Beda Mean dengan Menggunakan Uji Paired T-Test sebelum dan sesudah pada kelompok intervensi

Berikut ini merupakan hasil uji beda mean dengan uji Paired t-test sebelum dan sesudah intervensi pada kelompok intervensi: Tabel 9. Uji Beda Mean Dengan Menggunakan Uji Paired T-Test sebelum dan sesudah pada kelompok intervensi

\begin{tabular}{llll}
\hline & N & Mean & Sig \\
\hline Kualitas Asuhan & & & \\
Keperawatan & 34 & 1.3865 & \\
Sebelum Intevensi & & \\
Pada Kelompok & & \\
Intervensi & & \\
\hline $\begin{array}{l}\text { Kualitas Asuhan } \\
\text { Keperawatan }\end{array}$ & 34 & 1.6421 & \\
Sesudah Intevensi & & \\
Pada Kelompok & & \\
Intervensi & & \\
\hline
\end{tabular}

Hasil penelitian diatas menunjukkan menunjukkan bahwa nilai rata - rata (mean) kualitas asuhan keperawatan sebelum intevensi pada kelompok intervensi adalah 1.3865 dan kualiatas asuhan keperawatan sesudah intervensi pada kelompok intervensi adalah 1.6421 dari hasil tersebut dapat menunjukkan bahwa secara statistik deskriptif dapat disimpulkan bahwa ada perbedaan yang berarti antara kualitas asuhan keperawatan sebelum dan sesudah intevensi pada kelompok intervensi.

Berdasarkan hasil uji paired t-test di ketahui nilai sig (2-tailed) sebesar 0.00 dimana $<0.05$ maka dapat disimpulkan bahwa ada perbedaan yang signifikan antara 
kualitas asuhan keperawatan sebelum dan seudah intevensi pada kelompok intervensi.

\section{Uji Beda Mean dengan Menggunakan Uji Paired T-Test Sebelum dan Sesudah pada Kelompok Kontrol}

Berikut ini merupakan hasil uji beda mean dengan uji Paired t-test sebelum dan sesudah intervens pada kelompok kontrol :

Tabel 10. Uji Beda Mean Dengan Menggunakan Uji Paired T-Test sebelum dan sesudah pada Kelompok Kontrol

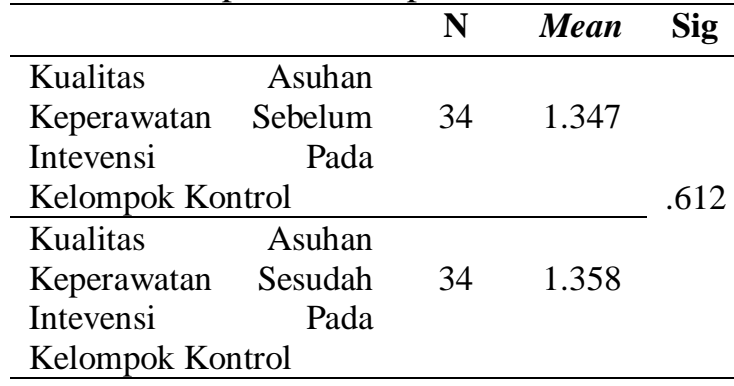

Hasil penelitian diatas menunjukkan menunjukkan bahwa nilai rata - rata (mean) kualitas asuhan keperawatan sebelum Intevensi Pada kelompok kontrol adalah 1.347 dan kualiatas asuhan keperawatan sesudah intervensi pada kelompok kontrol adalah 1.358 dari hasil tersebut dapat menunjukkan bahwa secara statistik deskriptif dapat disimpulkan bahwa tidak ada perbedaan yang berarti antara Kualitas Asuhan Keperawatan sebelum dan sesudah intevensi pada kelompok kontrol.

Berdasarkan hasil uji paired t-test di ketahui nilai sig (2-tailed) sebesar 0.612 dimana > 0.05 maka dapat disimpulkan bahwa tidak ada perbedaan yang signifikan antara kualitas asuhan keperawatan sebelum dan sesudah intevensi pada kelompok kontrol.

\section{PEMBAHASAN.}

Pengaruh Pelatihan dan Penerapan Model Metode Asuhan Keperawatan Profesional (MAKP) Primary Nursing Terhadap Kualitas Asuhan Keperawatan di Rumah Sakit Kota Medan

Hasil penelitian menunjukkan bahwa ada pengaruh penerapan model metode asuhan keperawatan profesional (MAKP) primary nursing terhadap peningkatan kualitas asuhan keperawatan, Berdasarkan hasil uji independend t-test di ketahui nilai sig (2-tailed) sebesar 0.00 dimana $<0.05$ maka dapat disimpulkan bahwa ada perbedaan yang signifikan antara kualitas asuhan keperawatan pada kelompok intervensi dengan kualitas asuhan keperawatan pada kelompok kontrol.

Hasil uji paired t-test juga menunjukkan nilai sig (2-tailed) sebesar 0.00 dimana $<0.05$ maka disimpulkan bahwa ada perbedaan yang signifikan antara kualitas asuhan keperawatan sebelum dan sesudah dilakukan intervensi.

Primary Nursing adalah model metode penugasan perawat pada unit pelayanan keperawatan dimana perawat memiliki tanggung jawap selama 24 jam dalam proses pemberian asuhan kepada pasien terhitung dari pasien masuk sampai dengan pasien keluar, metode ini meningkatkan kemandirian perawat dalam proses pemberian asuhan dari pengkajian sampai dengan evaluasi (Nursalam, 2014).

Model metode penugasan perawat primary nursing yaitu menggunakan seorang perawat primer yang bertanggung jawab terhadap 5-6 pasien dan jika perawat primer tidak bertugas maka akan dilimpakan kepada perawat pelaksana dalam proses pemberian asuhan yang sudah dibuat oleh perawat primer (Marquiz, dan Huston, 2000)

Metode penugasan primary nursing memiliki kelebihan yaitu bersifat berkelanjutan dan komprehensif, tidak membutuhkan perawat yang banyak tetapi membutuhkan tenaga yang sudah professional (Gillies, 1996). Asuhan keperawatan yang diberikan berkualitas tinggi, pasien merasakan lebih diutamakan dan dimanusiakan, dengan model primary nursing dokter dapat mengetahui dari perawat primer informasi terbaru dari pasien secara komprehensif dan terbaharui (Nursalam, 2014).

Hasil penelitian Molin et al, (2018) menyatakan bahwa model primary nursing juga dapat meningkatkan kepuasan pasien dan kualitas asuhan yang diberikan, hasil 
penetian Adelia (2019) juga menunjukkan bahwa ada peningkatan kepuasan perawat dan pasien setelah dilaksanakan penerapan Primary Nursing.

Kualitas keperawatan (quality nursing care) sebagai suatu proses yang berusaha untuk mencapai tingkat keunggulan tertinggi dalam memberikan perawatan, tanpa menyebabkan kerusakan, memenuhi kebutuhan, membantu untuk mencapai tujuan, pemeliharaan kesehatan dan pemulihan dari penyakit (Zhao, dan Akkadechanunt, 2011), kualitas keperawatan terfokus terhadap dua dimensi yaitu 1) apakah individu mendapatkan perawatan yang mereka butuhkan dan 2) apakah perawatan yang mereka terima telah efektif (Claessen. Et al, 2013), terdapat enam elemen inti asuhan keperawatan yang berkualitas yaitu 1) pendekatan holistik dengan kebutuhan fisik, mental dan emosional, berpusat pada pasien dan perawatan yang terus menerusterus menerus, 2) efisiensi dan efektivitas yang dikombinasikan dengan rasa kemanusiaan dan rasa iba, 3) profesional, praktik berbasis bukti yang berkualitas tinggi, 4) aman, efektif dan intervensi keperawatan yang tepat, 5) pemberdayaan pasien, dukungan dan advokasi, dan 6) pelayanan yang tulus melalui kerja sama tim yang efektif dengan profesi lain (Maben, dan Griffiths, 2008).

Pengumpulan data kualitas asuhan keperawatan dalam penelitian ini menggunakan instrumen Patient's Assessment of Quality Scale - Acute Care Version (PAQS-ACV), instrument ini dikembangkan untuk menilai kualitas asuhan keperawatan, instrumen Patient's Assessment of Quality Scale - Acute Care Version (PAQS-ACV) terdiri dari 44 pernyataan dengan lima domain kualitas yang meliputi caring, responsiveness, individualization, nurse characteristics dan environment. Berdasarkan hasil uji Content Validity Index (CVI) instrumen Patient's Assessment of Quality Scale - Acute Care Version (PAQS-ACV) diperoleh bahwa hasil CVI adalah 0.98 dan hasil uji reliabilitas ini menggunakan uji statistik cronbach alpha. hasil uji reliabilitas kuesioner Patient's Assessment of Quality Scale - Acute Care Version (PAQS-ACV) didapatkan nilai Cronbach Alpha yaitu 0,66 [13].

\section{KESIMPULAN}

Berdasarkan hasil Pengaruh Pelatihan dan penerapan model metode asuhan keperawatan profesional (MAKP) primary nursing terhadap kualitas asuhan keperawatan di rumah sakit kota medan maka dapat disimpulkan sebagai berikut:

1. Ada perbedaan yang signifikan antara kualitas asuhan keperawatan sesudah intevensi pada kelompok intervensi dengan kualitas asuhan keperawatan sesudah intervensi pada kelompok kontrol, hasil uji independend t-test menunjukkan nilai sig (2-tailed) sebesar 0.00 dimana $<0.05$.

2. Ada perbedaan yang signifikan antara kualitas asuhan keperawatan sebelum dan sesudah intevensi pada kelompok intervensi, hasil uji paired t-test menunjukkan nilai sig (2-tailed) sebesar 0.00 dimana $<0.05$.

\section{SARAN}

Berdasarkan hasil penelitian yang sudah dilaksanakn, disarankan untuk seluruh rumah sakit khususnya wilayah sumatera utara menerapkan model metode asuhan keperawatan profesional (MAKP) primary nursing dalam pelaksanaan tugas keperawatan di ruang rawat inap.

\section{REFERENSI}

Adelia, G. (2019). Pengembangan Model Penugasan Primary Nursing di Ruang Rawat InapRumah Sakit Universitas Sumatera Utara. Tesis : Fakultas Keperawatan Universitas Sumatera Utara.

Claessen, S. J. J., Francke, A. L., Sixma, H. J., Veer, A. J. E. de., \& Deliens, L. (2013). Measuring relatives' perspective on the quality of palliative care: the consumer quality index palliative. Care Journal of 
Pain and Symptom Management, 45(5), 875-884.

Gillies, D. E. (1996) Managemen keperawatan : Suatu Pendekatan Sistem. Edisi Kedua. W.B Saunders Company.

Izumi, S., Baggs, J.G., \& Knafl, K. A. (2011). Quality nursing care for hospitalized patients with advanced illness : Concept development. Res Nurs Health, 33(4), 299-315. doi:10.1002/nur.20391.

Lynn, M.R., McMillen, B. J., \& Sidani, S. (2008).Understanding and measuring patients' assessment of the quality of nursing care. Nursing Research, 56 (3), 159-166. doi: 10.1097/01.nnr.0000270025.52242.7 0

Maben, J., \& Griffiths, P. (2008). Nurses in society: Starting the debate. National Nursing Research Unit King's College London.

Marquiz, B. L., \& Huston, C. J. (2000). Leadership Roles and Management Functions in Nursing, Theory and Application Third Edition. Philadelphia: Lippincott.

Mendrofa, H.K. (2016). Hubungan budaya kerja perawat dengan kualitas asuhan keperawatan berdasarkan perspektif pasien di ruang rawat inap rumah sakit umum daerah dr. Pirngadi Medan. Tesis : Fakultas Keperawatan Universitas Sumatera Utara.

Molin, D. A., Gatta, C., Gilot, B.C., Ferrua, R., Cena, T., Manthey, M., \& Croso, A .(2018). The impact of primary nursing care pattern : result from a before-after study. Journal of Clinical Nursing, 2, 5-6

Nursalam. (2014). Manajemen Keperawatan: Aplikasi dalam praktik keperawatan profesional. Edisi 4. Jakarta: Salemba Medika.

Polit, D. F., \& Beck, C. T. (2012). Nursing research: Generating and assessing evidence of nursing practice. $9^{\text {th }}$ edition. Philadelphia: Lippincott Williams \& Wilkins.

Zhao, S. H., \& Akkadechanunt, T. (2011). Patients perceptions of quality nursing care in a chinese hospital. International Journal of Nursing and Midwifery, 3(9), 145-149. ISSN 2141-2499.

Zhao, S. H., Akkadechanunt, T., \& Xue, X. L. (2008). Quality nursing care as perceived by nurses and patients in a chinese hospital. Journal of Clinical Nursing, $\quad 18, \quad 1722-1728$. doi:10.1111/J.1365 2702.2008.02315. 